\title{
Observations of Wild Cougar (Puma concolor) Kittens with Live Prey: Implications for Learning and Survival
}

\author{
L. Mark Elbroch ${ }^{1}$ and Howard Quigley \\ Panthera, 8 West 40th Street, 18th Floor, New York, New York 10018 USA \\ ${ }^{1}$ Corresponding author (email: melbroch@panthera.org)
}

Elbroch, L. Mark, and Howard Quigley. 2012. Observations of wild Cougar (Puma concolor) kittens with live prey: implications for learning and survival. Canadian Field-Naturalist 126(4): 333-335.

The Cougar (Puma concolor) is a cryptic species in which social learning or opportunity learning has yet to be documented in the wild. "Opportunity teaching" is teaching in which an animal creates opportunities for conspecifics to observe or participate in operant learning. We present video data on an observation of Cougar kittens exhibiting social learning and inefficiency and inexperience in attempting to kill a live Mule Deer (Odocoileus hemionus) fawn. Our observations provide evidence for the importance of maternal care and they help explain why Cougar kittens less than a year of age have low survival rates.

Key Words: Cougar, Puma concolor, Mule Deer, Odocoileus hemionus, hunting, opportunity teaching, predation, social learning, Wyoming.

Cougars (Puma concolor) are a cryptic, solitary species difficult to observe, and one in which social learning, including opportunity learning, has yet to be documented in the wild. "Opportunity teaching" is a type of teaching observed in carnivores, during which an individual creates opportunities for conspecifics to observe or participate in operant learning (Caro and Hauser 1992; Hoppitt et al. 2008). In domestic cats (Felis catus), for example, successful predation incorporates the diverse skills of identifying prey, stalking prey, and manipulating and dispatching prey (Caro 1980), and kittens learn predation skills by observing the hunting behaviors of their siblings and mothers (Kuo 1930; John et al. 1968). Domestic cats exposed to particular prey types when they are kittens are more efficient at dispatching the same prey when they are adults (Caro 1980).

Many felids, as well as Meerkat (Suricata suricatta) parents and helpers, have been observed creating learning opportunities for developing offspring by presenting wounded prey, upon which younger animals can practice predation sequences (Caro 1987; Caro and Hauser 1992; Kitchener 1999; Thornton and Raihani 2010). In felids, the strongest evidence for this type of social learning has been documented in domestic cats and Cheetahs (Acinonyx jubatus) (Kruuk and Turner 1967 Caro and Hauser 1992; Kitchener 1999). For example, when Cheetah cubs are 5-7 months old, adult females catch and release $33 \%$ of their prey for their cubs to dispatch (Caro 1987; Caro 1994). By 10.5 months of age, incompetent Cheetah cubs are inefficiently attacking and beginning to consume $50 \%$ of prey captured by their mother. Adult female Cheetahs continue to increase learning opportunities for their cubs as they mature, and by the time cubs are 12.5 months old, mothers are catching and releasing 70\% of prey for their cubs to dispatch (Caro 1987; Caro
1994). The time needed for young felids to learn successful predation behaviors from their mothers is longest in the largest felids, which hunt large prey (Kitchener 1999).

Cougar kittens typically disperse between 12 and 24 months of age (Logan and Sweanor 2010), by which time they must be proficient hunters. Because hunting skills equate to survival, greater insights into when Cougar kittens develop efficient killing techniques might assist wildlife managers in predicting the survival of kittens orphaned at specific ages or in better understanding why kittens of particular ages are unable to survive on their own.

Orphaned or dispersing kittens are rarely monitored successfully enough to determine their fate. Nevertheless, it is assumed that orphaned or dispersed kittens less than 9 months old have a low chance of survival (Logan and Sweanor 2001). In a New Mexico study, 10 kittens $\leq 5$ months old died when orphaned, whereas a kitten 7.5 months old and another kitten 9.8 months old survived (Logan and Sweanor 2001). In a Utah study of 11 orphaned kittens, 5 died between the ages of 4 and 6 months, a 9-month-old was killed on a depredation permit after being independent for 6 weeks, and 5 others disappeared without researchers determining their fate (Stoner et al. 2006). In more recent research in the northern Yellowstone ecosystem and the Garnet Mountain area of Montana, 13 of 22 orphaned or dispersed kittens that became independent at less than one year of age survived (J. R. Newby, L. S. Mills, T. K. Ruth, D. H. Pletscher, M. S. Mitchell, H. B. Quigley, and K. M. Murphy, unpublished data).

As part of our study of Cougar ecology in the southern Yellowstone ecosystem, including Grand Teton National Park and the Bridger-Teton National Forest north of Jackson, Wyoming, we radio-collared adult 
Cougars (Vectronics, Berlin, Germany) and kittens (Telonics, Mesa, Ariz.) to study demographics and spatial and foraging ecology. Our work includes telemetry monitoring of individuals to document survivorship and cause-specific mortality, as well as field investigations of spatially aggregated GPS points (i.e., "GPS clusters") (see Anderson and Lindzey 2003), to search for and document prey remains. Here, we present data on a single observation of two 12-month-old Cougar kittens with a live Mule Deer (Odocoileus hemionus) fawn.

On 10 July 2012, at 1710, we opportunistically encountered a female Cougar (F61) and two female kittens (K1 with MOD-400 collar, K2 without collar) in thick brush at close range while we were conducting a routine site investigation of a GPS cluster. When the Cougars moved away, we discovered a live Mule Deer fawn at the site; the fawn had been attacked and its hind leg was broken. We set two remote cameras (Bushnell HD Max) at the site and departed the area at 1727. The cameras were set to capture 60-second videos when they were triggered by movement, with a 15 -second delay between potential trigger events.

We returned to pick up the cameras on 13 July, after the GPS collar worn by F61 relayed location data indicating the family group had departed the area. The two kittens were detected by the cameras at the site of the fawn at 2003 on the same day the cameras were set up. GPS data indicated that the adult female Cougar also returned to the site with her kittens, but she was never documented by the cameras. Both kittens were recorded at the site for 20 minutes before they pulled the Mule Deer fawn beyond the area recorded by the cameras. We discovered the remains of the fawn (rumen, 4 legs) approximately $25 \mathrm{~m}$ from the camera site.

Videos recorded the kittens' initial nervousness with the fawn (Supplementary Video Material, Part 1), exploratory predation behaviors, and social learning as they observed each other (Supplementary Video Material, Parts 2 and 3). Kittens nipped or bit the fawn on 13 occasions and swatted it with a paw 8 times during the 20 minutes they were recorded at the site; each contact elicited distress calls from the fawn. Only one kitten engaged the fawn at any one time, and the other sibling observed. K1 observed K2 interact with the fawn for a total of 2 minutes, and K2 observed K1 interact with the fawn for a total of 4.5 minutes. On 8 occasions, the kitten engaged with the fawn walked away from it or allowed the fawn to move away without restraining it. In the 20 minutes recorded by the cameras, the kittens were unsuccessful in killing the fawn. In Supplementary Video Material, Part 2, K2 observed as K1 swatted and nipped the fawn ineffectively, and chewed through and removed both ears. In Supplementary Video Material, Part 3, K1 observed while $\mathrm{K} 2$ swatted and pawed at the fawn, and then more efficiently secured a hold on its neck and dragged it from the view of the camera.
The fact that the adult female Cougar was present at the site but allowed her kittens to explore the fawn on their own, leads us to speculate that, in parallel with Cheetahs, she had initially wounded the fawn and then provided it to her kittens as a form of opportunity teaching. The inefficiency exhibited by the kittens and their unsuccessful exploratory predation behaviors further support the notion that the kittens were not responsible for the fawn's broken leg.

Here, we documented two kittens 12 months of age still developing the repertoire of predation behaviors required to be successfully independent. These observations provide evidence of maternal care requirements and social learning among conspecifics, and they provide a clearer picture of wild Cougar behavioral development. Our recorded observations demonstrate why kittens orphaned at less than a year of age are less likely to survive than older kittens, and they suggest that the time needed for Cougar kittens to develop complex predation behaviors for ungulate prey is greater than one year. In fact, the mean age of dispersal for 11 kittens in our project was 17.5 months (SE 0.6) (Newby 2011). The fact that 12-month-old kittens were recorded still developing their hunting skills has implications for conservation management aimed at mitigating the number of orphaned kittens and for management actions required for orphaned kittens.

Inexperienced Cougar kittens and sub-adults, both orphaned and dispersing, are disproportionately involved in conflicts with humans, including depredation of livestock and pets. Linnell et al. (1999) suggested that younger animals with unrefined hunting skills were more likely to attack livestock. Sixty-seven percent of 9 cougars in a Montana study (Aune 1991) and 33\% of 286 cougars in a California study (Torres et al. 1996) involved in depredation activity were less than two years old. Further, young Cougars are more likely to attack humans (Beier 1991).

Our observations provide evidence that Cougars up to 12 months of age are unlikely to have developed the full set of requisite skills needed to efficiently dispatch prey, and suggest that managers should consider both mitigating the potential for orphaned kittens as well as preparing to take action to mitigate potential problems caused by orphaned kittens.

\section{Acknowledgements}

Funding for this work was generously provided by the Richard King Mellon Foundation, the Charles Engelhard Foundation, the Summerlee Foundation, the Thaw Charitable Trust, L. and K. Westbrook, and a variety of individual donors. We thank J. Newby and P. Alexander for comments on an earlier version of the manuscript. We also thank our collaborators at Craighead Beringia South, for their ongoing support and involvement. 


\section{Literature Cited}

Anderson, C. R. Jr., and F. G. Lindzey. 2003. Estimating cougar predation rates from GPS location clusters. Journal of Wildlife Management 67: 307-316.

Aune, K. E. 1991. Increasing mountain lion populations and human-mountain lion interactions in Montana. Pages 86-94 in Mountain lion-human interaction symposium and workshop. Edited by C. S. Braun. Colorado Division of Wildlife, Denver, Colorado.

Beier, P. 1991. Cougar attacks on humans in the United States and Canada. Wildlife Society Bulletin 19: 403-412.

Caro, T. M. 1980. The effects of experience on the predatory patterns of cats. Behavioral and Neural Biology 29: $1-28$.

Caro, T. M. 1987. Indirect costs of play: cheetah cubs reduce maternal hunting success. Animal Behavior 35: 295-297.

Caro, T. M. 1994. Cheetahs of the Serengeti Plains: Group Living in an Asocial Species. University of Chicago Press, Chicago, Illinois. 500 pages.

Caro, T. M., and M. D. Hauser. 1992. Is there teaching in nonhuman animals? Quarterly Review of Biology 67: 151174.

Hoppitt, W. J. E., G. R. Brown, R. Kendal, L. Rendell, A. Thornton, M. M. Webster, and K. N. Laland. 2008. Lessons from animal teaching. Trends in Ecology and Evolution 23: 486-493.

John, R. E., P. Chesler, F. Bartlett, and I. Victor. 1968. Observational learning in cats. Science 159: 1489-1490.

Kitchener, A. C. 1999. Watch with mother: a review of social learning in the Felidae. Pages 236-258 in Mammalian Social Learning: Comparative and Ecological Perspectives. Edited by H. O. Box and K. R. Gibson. Cambridge University Press, Cambridge.
Kruuk, H., and M. Turner. 1967. Comparative notes on predation by lion, leopard, cheetah and wild dog in the Serengeti area, East Africa. Mammalia 31: 1-27.

Kuo, Z. Y. 1930. The genesis of the cat's responses to the rat. Journal of Comparative Psychology 11: 1-35.

Linnell, J. D. C., J. Odden, M. E. Smith, R. Aanes, and J. E. Swenson. 1999. Large carnivores that kill livestock: do "problem individuals" really exist? Wildlife Society Bulletin 27: 698-705.

Logan, K. A., and L. L. Sweanor. 2001. Desert Puma: Evolutionary Ecology and Conservation of an Enduring Carnivore. Island Press, Washington, DC. 464 pages.

Logan, K. A., and L. L. Sweanor. 2010. Behavior and social organization of a solitary carnivore. Pages 105-117 in Cougar: Ecology and Conservation. Edited by M. Hornocker and S. Negri. University of Chicago Press, Chicago, Illinois.

Newby, J. R. 2011. Puma dispersal in the Central Rocky Mountains. M.S. thesis, University of Montana, Missoula, Montana. 104 pages.

Stoner, D. C., M. L. Wolfe, and D. M. Choate. 2006. Cougar exploitation levels in Utah: implications for demographic structure, population recovery, and metapopulation dynamics. Journal of Wildlife Management 70: 1588-1600.

Thornton, A., and N. J. Raihani. 2010. Identifying teaching in wild animals. Learning and Behavior 38: 297-309.

Torres, S. G., T. M. Mansfield, J. E. Foley, T. Lupo, and A. Brinkhaus. 1996. Mountain lion and human activity in California: testing speculations. Wildlife Society Bulletin 24: $451-460$.

Supplementary video available at: http://www.canadianfieldnaturalist.ca

Received 2 October 2012

Accepted 27 November 2012 